\title{
Anti-inflammatory effects of enzyme-treated asparagus extract and its constituents in hepatocytes
}

\section{Mikio Nishizawa $^{1^{*}}$, Mana Kano ${ }^{1}$, Tetsuya Okuyama $^{1}$, Tadayoshi Okumura ${ }^{2,3}$ and Yukinobu Ikeya ${ }^{4}$}

${ }^{1}$ Department of Biomedical Sciences, College of Life Sciences, Ritsumeikan University, Kusatsu, Shiga, 525-8577, Japan; ${ }^{2}$ Research Organization of Science and Technology, Ritsumeikan University, Kusatsu, Shiga, 525-8577, Japan; ${ }^{3}$ Department of Surgery, Kansai Medical University, Hirakata, Osaka, 573-1191, Japan; ${ }^{4}$ Department of Pharmacy, College of Pharmaceutical Sciences, Ritsumeikan University, Kusatsu, Shiga, 525-8577, Japan

Corresponding Author: Mikio Nishizawa, MD, PhD, Department of Biomedical Sciences, College of Life Sciences, Ritsumeikan University, Kusatsu, Shiga, 525-8577, Japan

Submission date: November 3, 2015, Acceptance date: February 6, 2016; Publication date: February 9, 2016

\begin{abstract}
Background: Asparagus (Asparagus officinalis L.) is one of the most ancient vegetables in the world, and is rich in asparagine. Enzyme-treated asparagus extract (ETAS ${ }^{\text {TM; }}$ Amino Up Chemical Co., Ltd., Sapporo, Japan) is the final product of enzyme-treatment of asparagus stems and subsequent extraction. Two constituents were purified from ETAS and identified: 5-hydroxymethyl-2-furfural (HMF), an abundant constituent, and (S)-asfural, a novel constituent, which is a derivative of HMF. ETAS has been reported to increase the expression of heat shock proteins (HSPs), which are essential for the repair or removal of defective proteins. The expression of $H s p$ family genes is regulated by the transcription factor heat shock factor 1 (HSF1). It is unknown whether ETAS and its constituents elicit antiinflammatory effects, such as the suppression of nitric oxide (NO), an inflammatory mediator synthesized by inducible nitric oxide synthase (iNOS) in interleukin (IL)-1 $\beta$-treated hepatocytes.
\end{abstract}

Objective: To examine the anti-inflammatory effects of ETAS, we treated rat hepatocytes 
with ETAS, or its constituents $(S)$-asfural or HMF, and IL-1 $\beta$, before then analyzing the expression of the $i N O S$ gene and other genes involved in inflammation.

Methods: Primary cultured rat hepatocytes were prepared by collagenase perfusion. ETAS, $(S)$-asfural, or HMF was added to the medium with IL-1 $\beta$ and incubated at $37{ }^{\circ} \mathrm{C}$. When necessary, an inhibitor of HSF1 was added. NO in the medium was measured by the Griess method, and the half-maximal inhibitory concentration $\left(\mathrm{IC}_{50}\right)$ values were determined. To analyze the mRNA expression, a reverse transcription-quantitative polymerase chain reaction was performed. Antibody arrays were used to determine the levels of cytokines and chemokines in the medium.

Results: ETAS suppressed NO production in IL-1 $\beta$-treated hepatocytes without causing cytotoxicity. ETAS decreased the levels of both iNOS mRNA and the antisense transcript, whereas it increased the levels of Hsf1 mRNA and Hsp70 mRNA. ETAS also suppressed the production of pro-inflammatory cytokines and chemokines in hepatocytes. When (S)-asfural and HMF were added to the medium, they suppressed NO production and iNOS gene expression. The IC50 value of (S)-asfural was approximately 3-fold lower than that of HMF. In contrast, (S)-asfural increased the levels of Hsf1 mRNA. Interestingly, the KRIBB11, an inhibitor of HSF1, reduced the expression of the iNOS gene. When both (S)-asfural and KRIBB11 were added, the level of iNOS mRNA was lower than when (S)-asfural alone was added.

Conclusion: ETAS and its constituents $(S)$-asfural and HMF suppressed NO production and the expression of pro-inflammatory cytokines and chemokines, thus showing antiinflammatory effects. Our data suggest the possibility that the increased HSF1 level is involved in suppression of NO by ETAS and its constituents, although HSF1 is essential for the expression of the $i N O S$ gene.

Keywords: nitric oxide, inducible nitric oxide synthase, inflammation, heat shock factor, asparagus

\section{INTRODUCTION:}

Asparagus (Asparagus officinalis L.) is one of the most ancient vegetables among the asparagus species (family Liliaceae), which have been used as medicinal plants. Asparagus is rich in amino acids (e.g., asparagine, aspartic acid, leucine, alanine, and lysine), rutin (a 
flavonol glycoside), saponins, and phenolic compounds (e.g., caffeic and ferulic acids) $[1,2]$. Some of these compounds are bioactive, reducing the production of the inflammatory mediator nitric oxide (NO) and pro-inflammatory cytokines and chemokines [3].

Heat shock proteins (HSPs), such as HSP70 (also designated HSPA1A and HSPA1B), are induced by noxious stimuli or stresses (e.g., heat, inflammation, and fever) and demonstrate cytoprotective effects by repairing or removing defective proteins [4]. Heat shock factors (HSFs) are transcription factors that are activated by trimerization in response to stress, and then bind to cis-controlling elements in the promoters of Hsp family genes [5]. Among the four mammalian HSFs (i.e., HSF1-4), HSF1 is essential for HSP induction, whereas HSF2 modulates this induction [5]. Activated HSF1 plays a pivotal role in the induction of HSP to protect cells.

Asparagus extracts have been found to show high activity in the induction of Hsp70 mRNA during the screening of extracts of various crops in Hokkaido prefecture, Japan [6]. Enzyme-treated asparagus extract (ETAS ${ }^{\mathrm{TM}}$, Amino Up Chemical Co., Ltd., Sapporo, Japan) was developed as a functional food that is beneficial for human health [6]. ETAS is the final product processed by treating unused residual lower parts of green asparagus stems with enzymes and subsequently extracting with hot water. ETAS induces Hsp70 and heme oxygenase-1 mRNAs in neuroblastoma cells, showing cytoprotective effects [7]. A toxicological assessment of ETAS in rats [8] has supported its safety as a food and dietary supplement. Furthermore, ETAS attenuates the cognitive impairment of senescence-accelerated mouse prone 8 (SAMP8) mice, in which contextual fear memory (considered as a hippocampus-dependent memory) is significantly impaired [7].

Two bioactive constituents were purified from ETAS and identified: 5hydroxymethyl-2-furfural (HMF), i.e., an abundant constituent; and (S)-asfural, i.e., a novel constituent, which is (2-formylfuran-5-yl)methyl 5-oxopyrrolidine-2-carboxylate and a derivative of HMF [6]. ETAS increases the expression of Hsp70 mRNA in human promyelocytic leukemia cells [6]. Although the expression of Hsp family genes is regulated by HSF1 [5], it is unknown whether ETAS and its constituents exhibit antiinflammatory effects.

To examine the anti-inflammatory effects of ETAS and its constituents, we used interleukin (IL)-1 $\beta$-treated hepatocytes and monitored NO production. Inducible nitric oxide synthase (iNOS) produces this inflammatory mediator and nuclear factor $\kappa \mathrm{B}(\mathrm{NF}-\kappa \mathrm{B})$, which is a key transcription factor [9] that regulates the expression of the iNOS gene and the inflammatory genes. We also investigated the effects of the ETAS constituents on the 
expression of the genes that are involved in inflammation, such as the genes encoding iNOS, cytokines, and chemokines.

\section{MATERIALS AND METHODS:}

Materials: ETAS ${ }^{\mathrm{TM}}$ was generously provided by the Amino Up Chemical Co., Ltd. (Sapporo, Hokkaido, Japan). ETAS was produced from asparagus (A. officinalis L.) grown in Hokkaido and was manufactured according to the method described previously [6]. Briefly, green asparagus stems were extracted with hot water. The stems and extract $(\mathrm{pH} \mathrm{ca.} \mathrm{5)} \mathrm{were}$ treated with sucrase $\mathrm{C}$ as a cellulase (Mitsubishi-Kagaku Foods Corporation, Tokyo, Japan) at $60{ }^{\circ} \mathrm{C}$ for $1.5 \mathrm{~h}$ and then macerozyme $\mathrm{A}$ as a pectinase (Yakult Pharmaceutical Industry Co., Ltd., Tokyo, Japan) at $45{ }^{\circ} \mathrm{C}$ for $24 \mathrm{~h}$. After enzyme inactivation (121 $\left.{ }^{\circ} \mathrm{C}, 20 \mathrm{~min}\right)$ and centrifugation, the supernatant was mixed with dextrins (PINE-DEX; Matsutani Chemical Industry Co., Ltd., Hyogo, Japan) as a filler to attain even drying in the subsequent steps. The resultant solution was concentrated in vacuo, sterilized ( $\left.121^{\circ} \mathrm{C}, 45 \mathrm{~min}\right)$, and spray-dried to obtain the final product named 'ETAS powder'. In the investigation sample for this study, dextrins were included at $62.1 \%$ of the total weight. (S)-Asfural was kindly provided by Dr. Hideyuki Matsuura (Hokkaido University, Sapporo, Japan). HMF (greater than 99\% purity) and KRIBB11 were purchased from Sigma-Aldrich Corp. (St. Louis, MO, USA) and Merck Millipore Corp. (Darmstadt, Germany), respectively.

Primary cultured rat hepatocytes: Male Wistar rats were purchased from Charles River Laboratories Japan Inc. (Yokohama, Japan), housed at $21-23{ }^{\circ} \mathrm{C}$ and acclimatized. Hepatocytes were isolated from the livers by collagenase perfusion [10]. The isolated cells were resuspended in Williams' E (WE) medium (Sigma-Aldrich Corp.), seeded at $1.2 \times 10^{6}$ cells/dish, and incubated at $37^{\circ} \mathrm{C}$ overnight and analyzed the next day. All of the animal care and experimental procedures were carried out in accordance with the guidelines and laws of the Japanese government and were approved by the Animal Care Committee of Ritsumeikan University, Biwako-Kusatsu Campus.

Measurement of NO levels and lactate dehydrogenase (LDH) activity: ETAS powder was directly dissolved in WE medium and filter-sterilized for the assays. ETAS, or each constituent, was added to the hepatocyte medium with $1 \mathrm{nM}$ IL-1 $\beta$. If necessary, KRIBB11 [11] was added. After $8 \mathrm{~h}$ at $37^{\circ} \mathrm{C}$, the nitrite $\mathrm{NO}$ level (as nitrite) in the medium was measured using the Griess method [12,13]. To monitor cytotoxicity, the LDH activities in the medium were measured using LDH Cytotoxicity Detection Kits 
(Takara Bio Inc., Otsu, Shiga, Japan). Unless cytotoxicity was observed, the halfmaximal inhibitory concentrations $\left(\mathrm{IC}_{50}\right)$ were determined [14].

Western blot analysis: The hepatocytes were treated with IL-1 $\beta$ and each constituent at $37^{\circ} \mathrm{C}$, and whole-cell lysates were prepared [15]. The lysates were resolved by sodium dodecyl sulfate-polyacrylamide gel electrophoresis (SDS-PAGE) and blotted onto a Sequi-Blot membrane (Bio-Rad, Hercules, CA, USA). Immunostaining was performed using primary antibodies that were raised against rat iNOS (Thermo Fisher Scientific, Waltham, MA, USA) and rat $\beta$-tubulin (Cell Signaling Technology Inc., Danvers, MA, USA), followed by visualization with an ECL Blotting Detection Reagent (GE Healthcare Biosciences Corp., Piscataway, NJ, USA).

Measurement of the levels of cytokines and chemokines: The hepatocytes were incubated with ETAS, or each constituent in the presence or absence of IL-1 $\beta$ and incubated at $37{ }^{\circ} \mathrm{C}$ for $8 \mathrm{~h}$. The conditioned medium was subjected to enzyme-linked immunosorbent assay (ELISA) using Proteome Profiler Arrays, Rat Cytokine Array Panel A or a TNF- $\alpha$ Quantikine ELISA Kit (R\&D Systems, Minneapolis, MN, USA), as previously described $[16,17]$. The chemiluminescence of the spots on the arrays was detected by an LAS3000mini (GE Healthcare Biosciences Corp.) and measured by using ImageJ software (http://imagej.nih.gov/ij/). The average signals from the medium in the presence of both ETAS and IL-1 $\beta$ were compared to those in the presence of IL- $1 \beta$ alone.

Reverse transcription-polymerase chain reaction (RT-PCR): The hepatocytes were treated with IL-1 $\beta$ and/or each constituent at $37{ }^{\circ} \mathrm{C}$ for $4 \mathrm{~h}$, and the total RNA was prepared [18]. The cDNA was reverse-transcribed in a strand-specific manner with an oligo(dT) primer for mRNAs or with a sense primer for the iNOS antisense transcript (asRNA), and then quantitative PCR was performed [18] with paired primers (Table 1) and those described in $[17,19]$. Relative mRNA levels were estimated in triplicate by quantitative PCR with a Thermal Cycler Dice Real Time System (Takara Bio Inc.), and the obtained values were normalized to the internal control, elongation factor $1 \alpha(\mathrm{EF})$ mRNA [18].

Statistical analysis: The results in the figures and tables are representative of at least two independent experiments that yielded similar results. The values are presented as the means \pm 
standard deviation (SD). Differences were analyzed using Student's $t$-test. Statistical significance was set at $P<0.05$ and $P<0.01$.

Table 1: Primers used in this study.

\begin{tabular}{|c|c|c|c|}
\hline $\begin{array}{l}\text { Transcript } \\
\text { to be detected }\end{array}$ & Sequence $\left(5^{\prime} \longrightarrow 3^{\prime}\right)$ & $\mathrm{RT} / \mathrm{PCR}^{1}$ & Direction \\
\hline \multirow[t]{2}{*}{ iNOS mRNA } & CCAACCTGCAGGTCTTCGATG & PCR & Forward \\
\hline & GTCGATGCACAACTGGGTGAAC & PCR & Reverse \\
\hline \multirow[t]{3}{*}{ iNOS asRNA } & TGCCCCTCCCCCACATTCTCT & RT & Forward \\
\hline & ACCAGGAGGCGCCATCCCGCTGC & PCR & Forward \\
\hline & CAAGGAATTATACACGGAAGGGCC & PCR & Reverse \\
\hline \multirow[t]{2}{*}{ Hsfl mRNA } & GCTGGAGCCCGAGTGGGAACAG & PCR & Forward \\
\hline & AGGGTGGACACGCTGGTCACTT & PCR & Reverse \\
\hline \multirow[t]{2}{*}{ Hsp70 mRNA } & AGGAGATCTCGTCCATGGTGCT & PCR & Forward \\
\hline & TGGGCTCGTTGATGATCCGCAG & PCR & Reverse \\
\hline \multirow[t]{2}{*}{ EF mRNA } & TCTGGTTGGAATGGTGACAACATGC & PCR & Forward \\
\hline & CCAGGAAGAGCTTCACTCAAAGCTT & PCR & Reverse \\
\hline
\end{tabular}

\footnotetext{
${ }^{1} \mathrm{An}$ oligo(dT) primer used for reverse transcription (RT) to synthesize complementary DNA (cDNA) to mRNA. A sense primer used for RT to synthesize cDNA to the iNOS antisense transcript (asRNA). Primer pairs used for quantitative PCR.
}

\section{RESULTS:}

Qualification of ETAS lots: It has been reported that ETAS consists of carbohydrates, dietary fiber, protein, and several additional components [8]. We qualified several lots of ETAS powder and compared their makeup. ETAS powder included carbohydrates and proteins (Table 2), as well as amino acids and minerals, such as magnesium and iron (data not shown). These results confirmed that the deviation of quality among the lots of ETAS powder was not large. Therefore, we chose a lot (no. 111104) among them and used it for subsequent experiments. 
Table 2: Ingredients in the ETAS powder ${ }^{1}$

\begin{tabular}{lcl}
\hline Ingredient & Content of total weight & Analysis method \\
\hline Protein $^{2}$ & $8.6 \pm 1.3 \%$ & Kjeldahl method \\
Fats $^{2}$ & $1.0 \pm 0.2 \%$ & Acid decomposition method \\
Carbohydrate $^{2,3}$ & $84.4 \pm 1.8 \%$ & (Total weight) - (Protein) - (Fats) \\
& $3.4 \pm 0.4 \%$ & - (Ash contents) - (Water) \\
Ash contents $^{2}$ & $2.6 \pm 0.4 \%$ & Direct ashing method \\
Water $^{2}$ & $30.3 \pm 7.1 \%$ & Reduced-pressure drying method \\
& $292 \pm 240 \mathrm{mg} / 100 \mathrm{~g}$ & HPLC \\
Glucose $^{2}$ & $233 \pm 141 \mu \mathrm{g} / 100 \mathrm{~g}$ & HPLC \\
HMF $^{4}$ & &
\end{tabular}

\footnotetext{
${ }^{1}$ Data kindly provided by Amino Up Chemical Co., Ltd. (unpublished data). ${ }^{2}$ Represented as the mean \pm SD ( $n$ = 4). ${ }^{3}$ Dextrins were included at $48-62 \%$ of the total weight. ${ }^{4}$ Analyzed using high-performance liquid chromatography (HPLC) by Ito et al. [8] and represented as the mean $\pm \operatorname{SD}(n=3)$.
}

ETAS suppresses iNOS gene expression: We used primary cultured rat hepatocytes and examined the effects of ETAS on NO production. ETAS powder was dissolved in WE medium, and NO production was monitored in the presence of IL-1 $\beta$ in the hepatocytes. As shown in Figure 1A, ETAS decreased the NO production that was induced in a dose-dependent manner by IL-1 $\beta$. LDH activity did not increase by the addition of ETAS (data not shown), suggesting that ETAS did not cause cytotoxicity. The $\mathrm{IC}_{50}$ value of ETAS was $1.69 \pm 0.42 \mathrm{mg} / \mathrm{ml}(n=4)$. The western blot analysis indicated that the iNOS protein decreased dose-dependently when ETAS was added (Figure 1B). Furthermore, ETAS also reduced the levels of iNOS mRNA (Figure 1C).

A

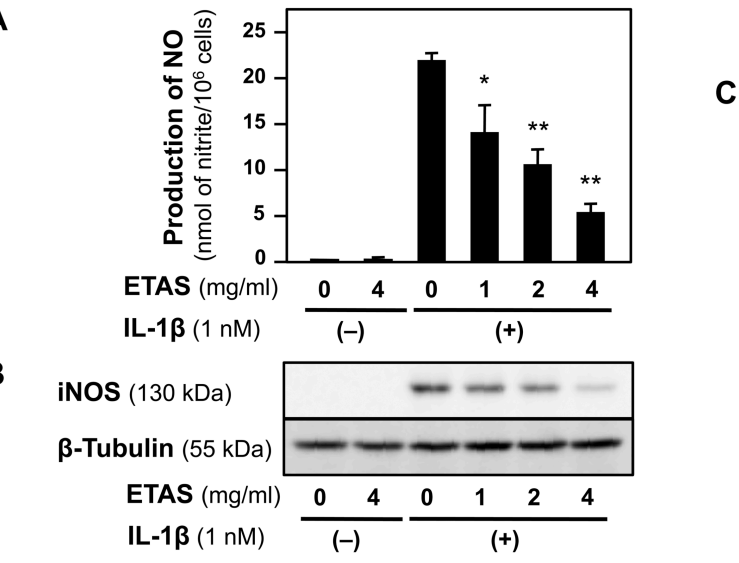

C

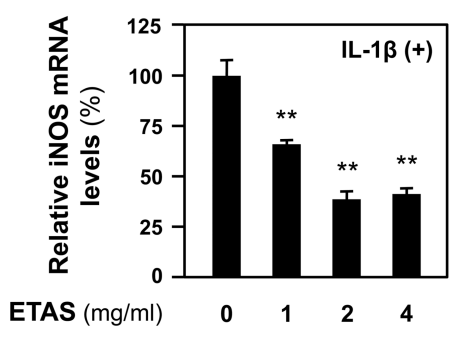

$\operatorname{IL-1\beta }(1 \mathrm{nM}) \frac{0}{(-)} \frac{4}{(+)} \frac{1}{2}$

Figure 1: ETAS suppresses $i N O S$ gene expression in IL-1 $\beta$-treated hepatocytes. (A) The effects of ETAS on the induction of NO production. The hepatocytes were treated with IL-1 $\beta$ and/or ETAS at $37^{\circ} \mathrm{C}$ for 
$8 \mathrm{~h}$. The NO levels in the medium were measured (mean $\pm \mathrm{SD}, n=3$ ). $* P<0.05$ and $* * P<0.01$ versus IL- $1 \beta$ alone. (B) The effects of ETAS on the induction of iNOS protein. Whole cell extracts from the hepatocytes were resolved using SDS-PAGE and detected with an anti-iNOS or anti- $\beta$-tubulin antibody. (C) The effects of ETAS on iNOS mRNA expression. The hepatocytes were treated similarly for $4 \mathrm{~h}$. The total RNA was analyzed using quantitative RT-PCR. The iNOS mRNA levels (mean $\pm \mathrm{SD}, n=3$ ) were normalized to EF mRNA, and the value in the presence of IL- $1 \beta$ alone was set at $100 \%$. ** $P<0.01$ versus IL- $1 \beta$ alone.

Next, we investigated the time course of NO production and iNOS mRNA expression after the addition of ETAS and IL-1 $\beta$. As shown in Figure 2A, the NO production was induced in a time-dependent manner by IL-1 $\beta$, whereas the NO levels in the presence of ETAS (i.e., ETAS + IL-1 $\beta$ ) were low. Western blot analysis demonstrated that ETAS decreased iNOS protein (Figure 2B). When the direct quenching activity of ETAS was measured, according to a previously published method [13], ETAS did not significantly quench NO in vitro (data not shown). Together, all of this data suggests that ETAS reduces the expression of iNOS mRNA, thereby decreasing iNOS protein and leading to a decrease of NO production in the hepatocytes. The data implies that ETAS may suppress the expression of the iNOS gene at the transcriptional level in the hepatocytes.
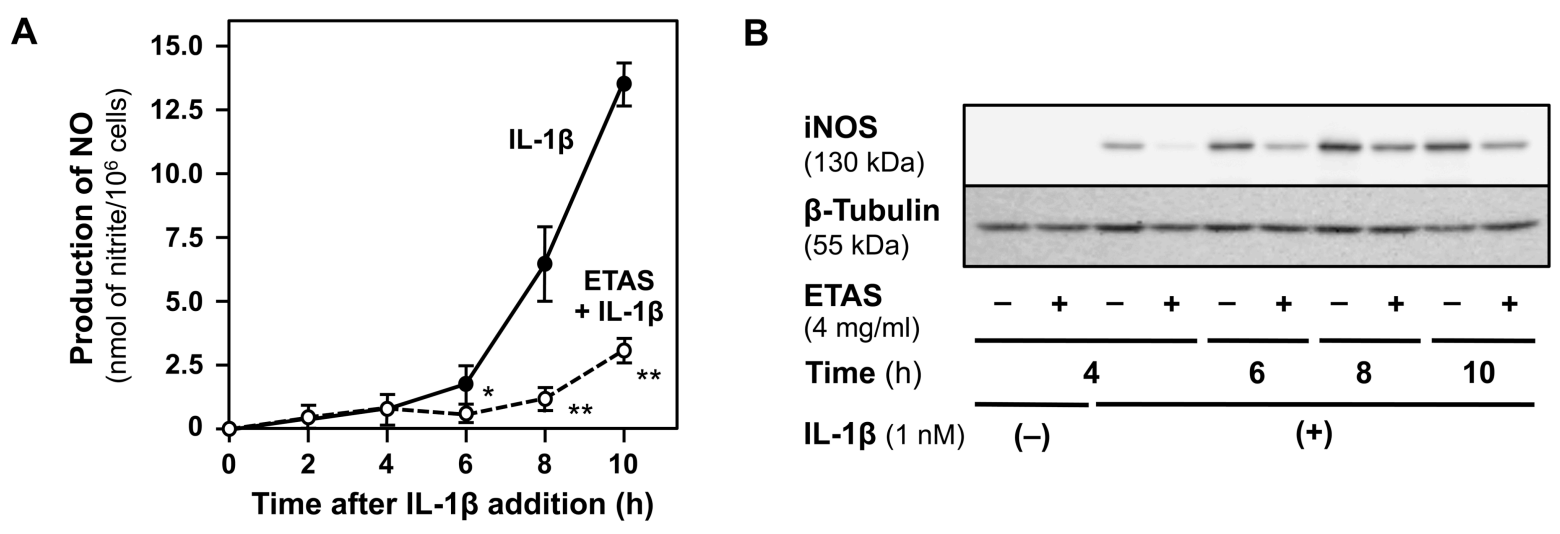

Figure 2: ETAS suppresses iNOS expression in IL-1 $\beta$-treated hepatocytes. (A) Time course of NO production in the presence of ETAS. The hepatocytes were treated with $1 \mathrm{nM} \mathrm{IL-} 1 \beta$ and/or $4 \mathrm{mg} / \mathrm{ml}$ ETAS at $37{ }^{\circ} \mathrm{C}$ for the indicated time. The NO levels in the medium were measured (mean $\pm \mathrm{SD}$, $n=3) .{ }^{*} P<0.05$ and $* * P<0.01$ versus IL- $1 \beta$ alone. (B) The effects of ETAS on the induction of iNOS protein. Whole cell extracts from the hepatocytes were resolved using SDS-PAGE and detected with an anti-iNOS or anti- $\beta$-tubulin antibody.

ETAS suppresses the induction of inflammatory cytokines and chemokines: To examine whether ETAS suppressed the production of cytokines and chemokines that are involved in inflammation, we measured them with ELISA. As shown in Table 3, these assays indicated 
that ETAS reduced IL-1 $\beta$-induced production of tumor necrosis factor $\alpha$ (TNF- $\alpha)$ and chemokines, including chemokine (C-C motif) ligand 20 (CCL20), chemokine (C-X-C motif) ligand 1 (CXCL1), and chemokine ( $\mathrm{C}-\mathrm{X}_{3}-\mathrm{C}$ motif) ligand 1 (CX3CL1). These chemokines induce leukocyte trafficking in the immune system [20].

To confirm these results, we measured the levels of these mRNAs. As shown in Table 3, ETAS significantly decreased the levels of the mRNAs encoding TNF- $\alpha$, IL-6, CCL2, and CX3CL1, whose expression is regulated by NF-kB [9]. Therefore, ETAS suppressed the production of not only the inflammatory mediator NO but also several inflammatory cytokines and chemokines. The data suggests that ETAS is involved in the suppression of inflammation.

Table 3: Suppression of cytokine/chemokine production by ETAS in hepatocytes

\begin{tabular}{lcc}
\hline Cytokine/chemokine (abbreviation) & $\begin{array}{c}\text { Protein level [\%] } \\
\text { (ETAS+IL-1 } \beta)^{1}\end{array}$ & $\begin{array}{c}\text { mRNA level [\%] } \\
\text { (ETAS+IL-1 } \beta)^{2}\end{array}$ \\
\hline Tumor necrosis factor- $\alpha$ (TNF- $\alpha$ ) & 20.4 & $40.3 \pm 1.2^{* *}$ \\
Interleukin-6 (IL-6) & not determined & $28.5 \pm 3.3^{* *}$ \\
Chemokine (C-C motif) ligand 2 (CCL2) & not determined & $18.0 \pm 8.4^{* *}$ \\
Chemokine (C-C motif) ligand 20 (CCL20) & 84.9 & $37.3 \pm 3.5$ \\
Chemokine (C-X-C motif) ligand 1 (CXCL1) & 80.1 & $98.5 \pm 7.1$ \\
Chemokine (C-X 3 -C motif) ligand 1 (CX3CL1) & 0.0 & $19.7 \pm 2.3^{* *}$ \\
\end{tabular}

\footnotetext{
${ }^{1}$ The levels of cytokines and chemokines in the medium were measured by ELISA. The relative protein levels are the percentage means of the ratios comparing the spot signals of the corresponding arrays. The protein levels in the presence of IL- $1 \beta$ alone were set at $100 \%$. ${ }^{2}$ The relative mRNA levels were measured by quantitative RTPCR. $* P<0.05$ and $* * P<0.01$ versus IL- $1 \beta$ alone (100\%).
}

ETAS induces Hsp70 and Hsf1 mRNAs: Next, we examined whether ETAS enhanced the expression of Hsp70 mRNA in IL-1 $\beta$-treated hepatocytes. As expected from previous studies in other cell lines [6,7], the quantitative RT-PCR showed that ETAS also increased the levels of Hsp70 mRNA in hepatocytes (Figure 3A).

Afterwards, the expression of Hsfl mRNA was analyzed. As shown in Figure 3B, ETAS increased the levels of Hsfl mRNA, suggesting that the ETAS-induced increase of Hsfl mRNA leads to the induction of Hsp70 mRNA. 
A

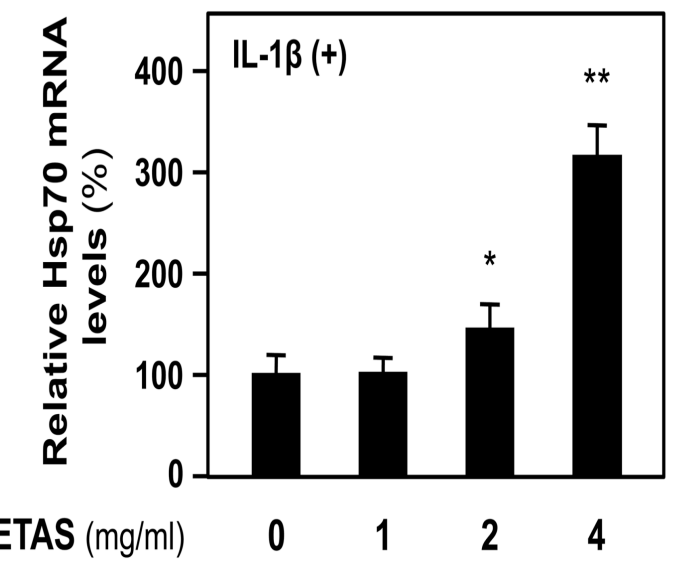

B

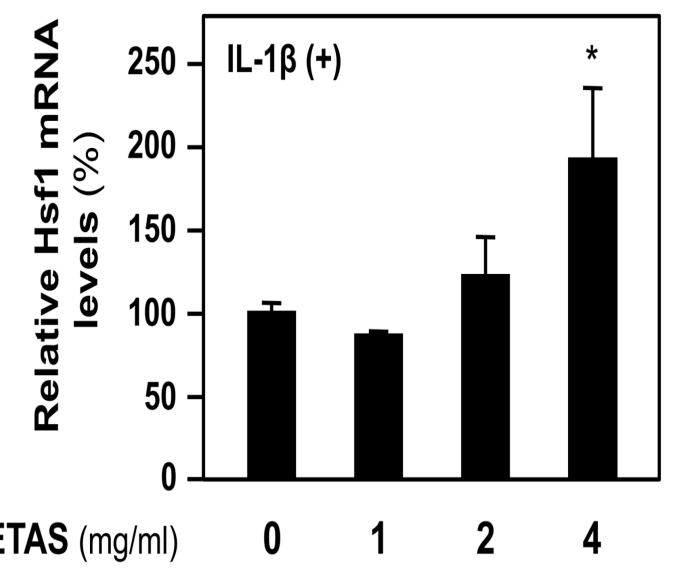

Figure 3: ETAS enhances the expression of Hsp70 and Hsf1 mRNAs in hepatocytes. The hepatocytes were treated with ETAS and IL-1 $\beta(1 \mathrm{nM})$ at $37^{\circ} \mathrm{C}$ for $4 \mathrm{~h}$. The total RNA was analyzed using quantitative RT-PCR. The levels of Hsp70 mRNA (A) and Hsf1 mRNA (B) were normalized to EF mRNA (mean $\pm \mathrm{SD}, n=3$ ). $* P<0.05$ and $* * P<0.01$ versus IL- $1 \beta$ alone $(100 \%)$.

(S)-Asfural and HMF suppress the expression of the $i N O S$ gene: We further investigated which constituent(s) of ETAS had NO suppressive activity. Dextrins and glucose, which are two major constituents of ETAS (Table 2), did not significantly affect the NO production in hepatocytes (data not shown). The bioactive constituents identified were $(S$ )-asfural and HMF [6], both of which have furfural skeletons (Figure 4A). When $(S)$-asfural and HMF were added to the medium, they suppressed NO production in the presence of IL-1 $\beta$ (Figure 4B). The addition of these constituents at the concentrations up to $1000 \mu \mathrm{M}$ did not increase LDH activity of the medium (data not shown), suggesting that both constituents did not cause cytotoxicity. The $\mathrm{IC}_{50}$ value of $(S)$-asfural $(326 \mu \mathrm{M})$ was lower than that of HMF $(855 \mu \mathrm{M})$, suggesting that $(S)$-asfural is 2.6-fold more potent than HMF.The western blot analysis of the hepatocytes indicated that $(S)$-asfural and HMF decreased the levels of iNOS protein (Figure 4C). Furthermore, the quantitative RT-PCR demonstrated that $(S)$-asfural and HMF reduced the iNOS mRNA expression. (Figure 4D). In contrast, (S)-asfural increased the levels of Hsf1 mRNA (data not shown). Together, our results indicate that (S)-asfural and HMF suppress the expression of the $i N O S$ gene in a similar manner as ETAS. 
A

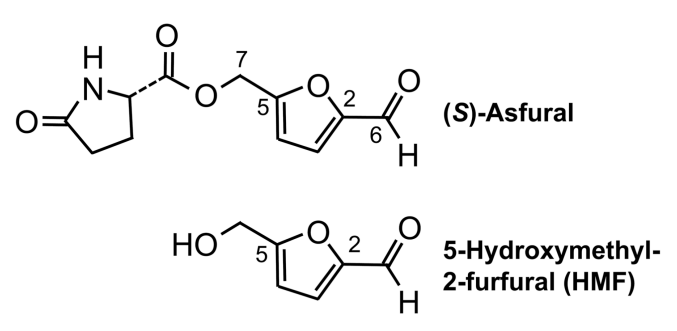

B

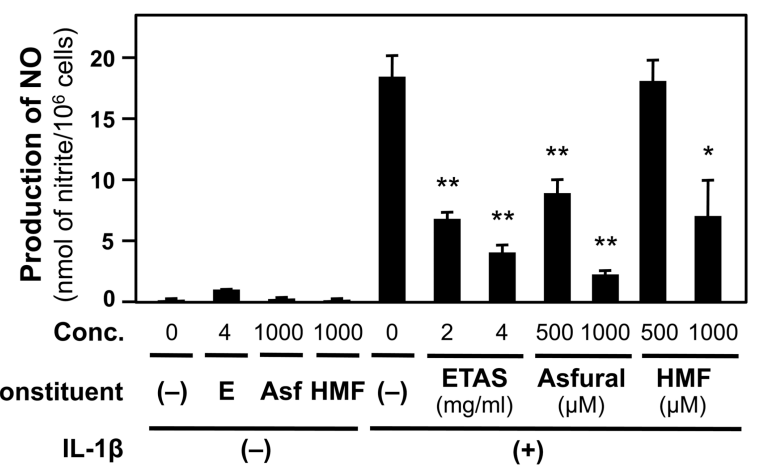

C

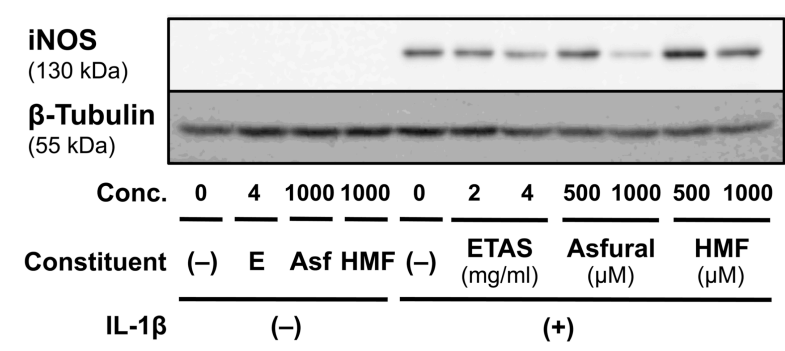

D

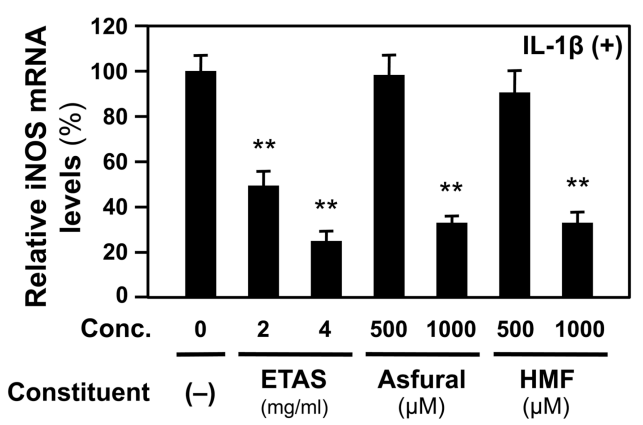

Figure 4: $(S)$-Asfural and HMF suppress the expression of the $i N O S$ gene. (A) Chemical structures of the bioactive constituents of ETAS. (B) The effects of the constituents on the induction of NO production. The hepatocytes were treated with IL- $1 \beta$ and/or each constituent at $37{ }^{\circ} \mathrm{C}$ for $8 \mathrm{~h}$. The NO levels in the medium were measured (mean $\pm \mathrm{SD}, n=3$ ). ${ }^{*} P<0.05$ and $* * P<0.01$ versus IL-1 $\beta$ alone. (C) The effects of the constituents on the expression of iNOS protein. Whole cell extracts from the hepatocytes were subjected to a western blot analysis with an anti-iNOS or anti- $\beta$-tubulin antibody. (D) The effects of the constituents on the expression of iNOS mRNA. The hepatocytes were similarly treated for $4 \mathrm{~h}$. The total RNA was analyzed using quantitative RT-PCR. The mRNA levels were normalized to EF mRNA (mean $\pm \mathrm{SD}, n=3)$. ${ }^{* *} P<0.01$ versus $\mathrm{IL}-1 \beta$ alone $(100 \%)$.

iNOS asRNA is decreased by ETAS, $(\boldsymbol{S})$-asfural, and HMF: iNOS induction is also regulated via a post-transcriptional mechanism that is mediated by the asRNA transcribed from the $i N O S$ gene [18]. The iNOS asRNA interacts with and stabilizes iNOS mRNA [18,21]. Herbal constituents, such as chlorogenic acid [3], gomisin $N$ [15], and shisoflavanone A [16], decrease the levels of iNOS asRNA, leading to decreased iNOS mRNA expression. Therefore, we examined whether ETAS or its constituents affect the expression of the iNOS asRNA. As shown in Figure 5, ETAS, $(S)$-asfural, and HMF reduced the levels of iNOS asRNA in the presence of IL-1 $\beta$. These results correlate with those of the NOS mRNA levels (Figures 1C,4D). 


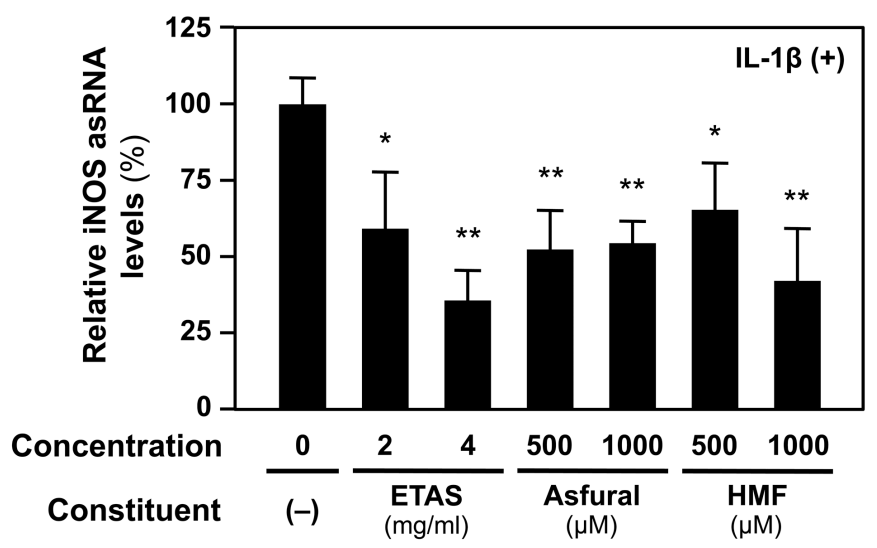

Figure 5: ETAS and its constituents reduce the levels of iNOS asRNA. The hepatocytes were treated with each constituent and IL- $1 \beta$ at $37{ }^{\circ} \mathrm{C}$ for $4 \mathrm{~h}$. The total RNA was subjected to strand-specific RT$\mathrm{PCR}$. The data represent the levels of iNOS asRNA (mean $\pm \mathrm{SD}, n=3$ ). A negative control PCR using total RNA without RT did not amplify (data not shown). ${ }^{*} P<0.05$ and $* * P<0.01$ versus IL-1 $\beta$ alone (100\%).

The HSF1 inhibitor KRIBB11 decreases the expression of the $i N O S$ gene: We examined the involvement of HSF1, which regulates the expression of the Hsp family genes, in the expression of the $i N O S$ gene. Therefore, KRIBB11, an inhibitor of HSF1 [11], was added to the medium (Figure 6A). KRIBB11 treatment reduced NO production in the IL-1 $\beta$-treated hepatocytes, similarly to ETAS treatment. Furthermore, KRIBB11 decreased the IL-1 $\beta$ induced expression of iNOS mRNA (Figure 6B), implying that HSF1 is involved in iNOS induction.

Finally, we investigated the effects of HSF1 on $i N O S$ gene expression in the presence of $(S)$-asfural. When both KRIBB11 and $(S)$-asfural were added, the level of iNOS mRNA was significantly lower than when KRIBB11 or $(S)$-asfural alone was added (Figure 6C).

A

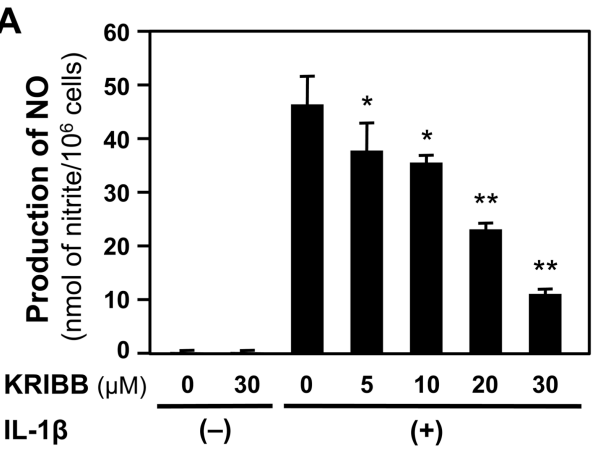

B

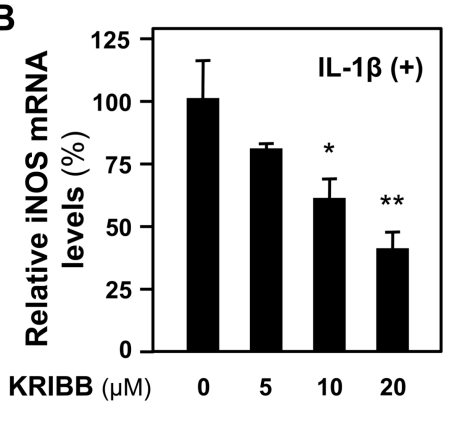

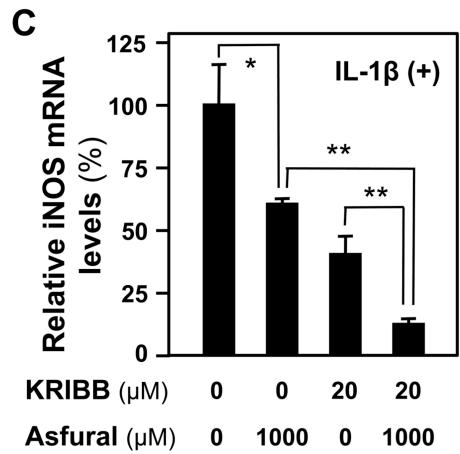

Figure 6: Both KRIBB11 and (S)-asfural affect the expression of the $i N O S$ gene. (A) The effects of KRIBB11 on NO production. The hepatocytes were treated with KRIBB11 or ETAS in the presence of IL-1 $\beta$ for $8 \mathrm{~h}$, and the NO levels in the medium were measured (mean $\pm \mathrm{SD}, n=3$ ). ${ }^{*} P<0.05$ and ${ }^{* *} P<0.01$ versus IL$1 \beta$ alone. (B,C) The effects of KRIBB11 and (S)-asfural on the expression of iNOS mRNA. The hepatocytes 
were treated with KRIBB11 and/or $(S)$-asfural in the presence of IL-1 $\beta$ for 4 h, and the total RNA was analyzed using quantitative RT-PCR. The mRNA levels were normalized to EF mRNA (mean $\pm \mathrm{SD}, n=3$ ). $* P<0.05$ and $* * P<0.01$ versus IL-1 $\beta$ alone $(100 \%)$.

\section{DISCUSSION:}

This study demonstrated that ETAS and its constituents, $(S)$-asfural and HMF, demonstrated anti-inflammatory effects by suppressing the production of the inflammatory mediators NO and pro-inflammatory cytokines and chemokines in IL-1 $\beta$-treated hepatocytes. As far as we know, there are no reports that have described the anti-inflammatory effects of Asparagus officinalis extract. The comparison of the $\mathrm{IC}_{50}$ values of the NO inhibition indicated that $(S)$ asfural had a higher potency than HMF, although the content of $(S)$-asfural was much smaller than HMF (Table 2). Given that the $\mathrm{IC}_{50}$ value of ETAS was much higher than those of $(S)$ asfural and HMF, bioactive small molecules, other than these constituents, are expected to be included in ETAS. Indeed, when ETAS solution was ultrafiltrated, the filtrate through the membrane with a molecular weight cut-off (MWCO) value of 2,000 Daltons showed an NO suppression activity comparable to that of ETAS (unpublished data). Recently, four constituents isolated from asparagus inhibited the production of fibrotic matrix and the accumulation of TNF- $\alpha$ [22]. These constituents may possess NO suppressive activity.

We used only primary cultured rat hepatocytes in this study. To clarify the antiinflammatory effects of ETAS and its constituents, other cell lines should be investigated in the future. Additionally, there are several reports about the administration of ETAS to animals or healthy adult men. However, anti-inflammatory effects of ETAS were not observed or examined in details $[7,8,23,24]$. Therefore, the anti-inflammatory effects in vivo remain to be studied.

Both HMF and $(S)$-asfural have aldehyde groups of their furfural skeletons (Figure 4A). Consequently, they are expected to scavenge reactive oxygen species. Recently, Okutsu et al. have reported that one of the antioxidants in heat-processed koji (i.e., culture of Aspergillus species) was identified as HMF [25]. Accordingly, $(S)$-asfural is also expected to possess the scavenging activity.

We found that Hsfl and Hsp70 mRNAs increased by ETAS in the IL-1 $\beta$-treated hepatocytes without heat shock (e.g., 40-43 $\left.{ }^{\circ} \mathrm{C}\right)$. In ETAS-treated NG108-15 neuronal cells, the expression of mRNAs encoding HSF1, HSP70, and heme oxygenase-1 (HO-1; a cytoprotective enzyme, also called HSP32) increased [7]. The HSF1 inhibitor KRIBB11 reduced the IL-1 $\beta$-induced expression of iNOS mRNA (Figure 6). It has been reported that KRIBB11 binds to HSF1 and inhibits the HSF1-dependent recruitment of the positive 
transcription elongation factor $\mathrm{b}(\mathrm{p}-\mathrm{TEFb})$ to the $H s p 70$ gene promoter [11]. Similarly, HSF1 seems to be required for the expression of the $i N O S$ gene and is involved in the suppression of its expression by ETAS.

Additionally, the increased HSF1 level may be involved in the NO suppression by ETAS and its constituents (Figure 6). Goldring et al. have reported that HSF1 binds to HSF1binding sites (HSEs) [4] in the promoter of the mouse iNOS gene when macrophages are treated with heat shock at $41{ }^{\circ} \mathrm{C}$ or bacterial lipopolysaccharide (LPS) [26]. In the rat iNOS promoter (DDBJ/EMBL/GenBank accession No. AB290142), several potential HSEs are present, which may explain why HSF1 modulates the expression of the iNOS gene. The putative action of HSF 1 on the expression of the $i N O S$ gene is schematically shown in Figure 7.

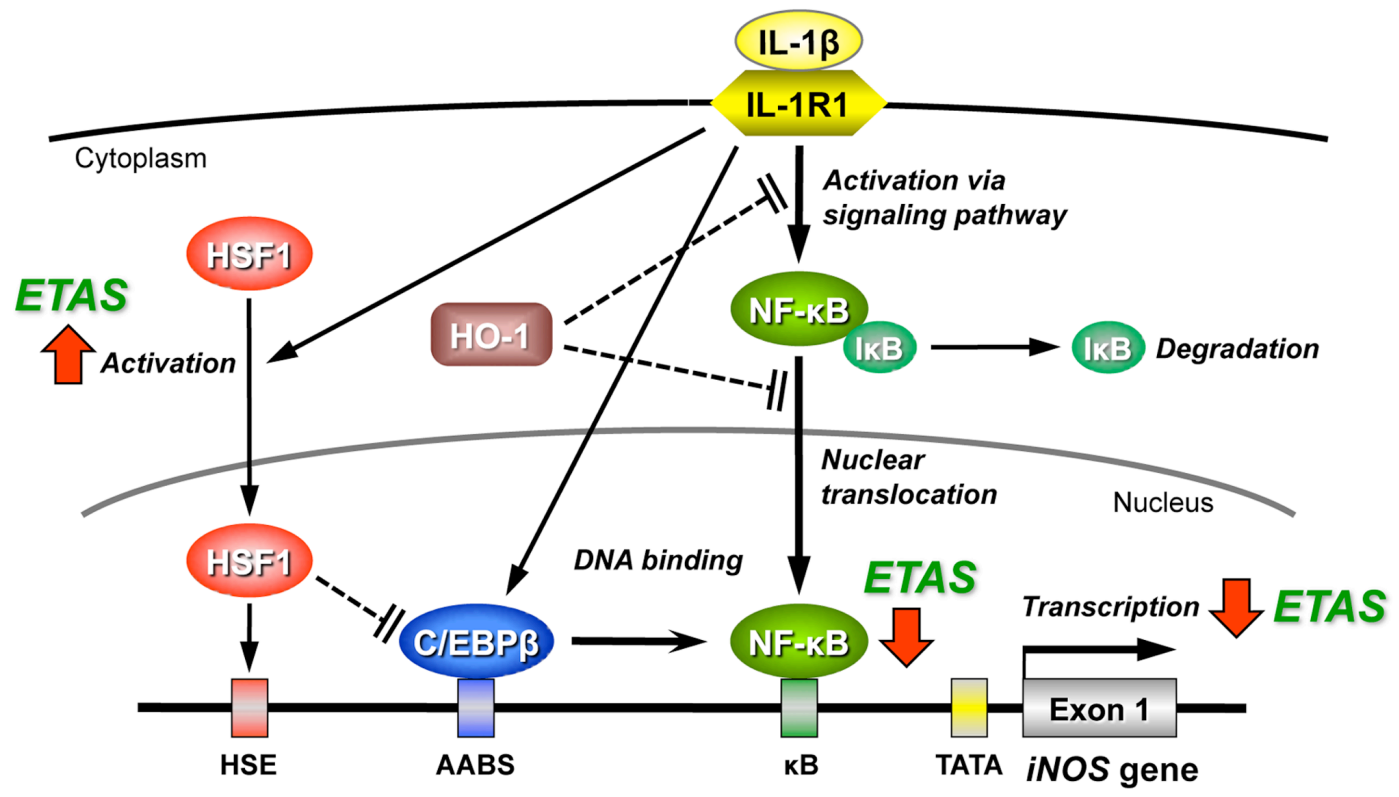

Figure 7: A putative model for the suppression of the iNOS gene by ETAS in hepatocytes.

Three transcription factors that are involved in the expression of the $i N O S$ gene in hepatocytes are schematically depicted. The IL-1 $\beta$ signal primarily activates NF- $\kappa B$ through the IL-1 receptor, type I (IL1R1). Through its signal transduction pathway, NF-kB transactivates the $i N O S$ gene by binding to a $\kappa \mathrm{B}$ site $[15,28]$. $\mathrm{C} / \mathrm{EBP} \beta$ binds to an A-activator-binding site (AABS) site and interacts with NF- $\mathrm{BB}$, resulting in the synergistic enhancement of $i N O S$ gene transcription [28]. In response to an IL-1 $\beta$ signal, activated HSF1 binds to an HSE and antagonizes C/EBP $\beta$ by direct interaction with C/EBP $\beta$ [27]. ETAS may activate HSF1, allowing it to interact with $\mathrm{C} / \mathrm{EBP} \beta$ and leading to the decreased transactivation activity of NF- $\kappa$ B. The bold arrows show the effects of ETAS. Heme oxygenase-1 (HO-1) may be involved in the effects of ETAS by inhibiting the activation of NF- $\mathrm{BB}$ [29]. 
What is the missing link between HSF1 and NF- $\mathrm{BB}$, which primarily regulates the expression of the $i N O S$ gene and other inflammatory genes? In response to noxious stimuli or stresses, activated HSF1 binds to another transcription factor CCAAT/enhancer-binding protein $\beta(\mathrm{C} / \mathrm{EBP} \beta)$ and antagonizes the activity of $\mathrm{C} / \mathrm{EBP} \beta$, which enhances the transcription of the $I L-1 \beta$ gene [27]. However, C/EBP $\beta$ interacts with NF- $\kappa \mathrm{B}$ and synergistically activates the transcription of the iNOS gene in rat hepatocytes [28]. It is likely that HSF1 antagonizes $\mathrm{C} / \mathrm{EBP} \beta$ and thereby negatively regulates the NF- $\kappa \mathrm{B}$ activity at the $i N O S$ promoter (Figure 7). Therefore, ETAS may activate HSF1 to interact with $\mathrm{C} / \mathrm{EBP} \beta$, resulting in the decreased transactivation activity of NF- $\mathrm{BB}$. When HO-1 is induced by cytokines or LPS, it suppresses $\mathrm{NF}-\kappa \mathrm{B}$ by inhibiting the activation processes, including nuclear translocation of NF- $\kappa \mathrm{B}$ [29]. If HO-1 is induced by ETAS in hepatocytes, it is possible that ETAS inhibits NF- $\kappa$ B activity through HO-1. Furthermore, it cannot be ruled out that ETAS may directly affect the DNAbinding activity of NF- $\mathrm{KB}$ in the nucleus. More studies are required to clarify the roles of HSF1 in $i N O S$ gene expression, as well as the actions of ETAS.

CONCLUSION: ETAS and its constituents suppressed the production of NO and proinflammatory cytokines and chemokines, all of which may be responsible for the antiinflammatory effects of ETAS. Our results imply that the increased HSF1 level may be involved in the NO suppression by ETAS and its constituents. Therefore, ETAS may be beneficial as a functional food with anti-inflammatory activity.

Abbreviations: NO, nitric oxide; HSP, heat shock protein; HSF, heat shock factor; ETAS, enzyme-treated asparagus extract; HMF, 5-hydroxymethyl-2-furfural; IL, interleukin; iNOS, inducible nitric oxide synthase; $\mathrm{IC}_{50}$, half-maximal inhibitory concentration; RT, reverse transcription; PCR, polymerase chain reaction; EF, elongation factor $1 \alpha$; asRNA, antisense transcript; NF- $\kappa \mathrm{B}$, nuclear factor $\kappa \mathrm{B}$.

\section{Authors' contributions}

M.N. and M.K. contributed equally to this study. All of the authors were involved in performing the experiments and preparing the manuscript.

Competing Interests: M.N., T., and Y.I. received a research grant from the Amino Up Chemical Co., Ltd. M.N. is an academic manager of the International Congress on Nutrition and Integrative Medicine (ICNIM; Sapporo, Japan). ICNIM functions to carry out basic and clinical research related to AHCC and other complementary and alternative medicine (CAM) 
approaches and aims at contributing to the development of CAM, in which AHCC and other compounds can be used for human health. M.K. performed this study as a graduate student of the Graduate School of Life Sciences, Ritsumeikan University.

\section{Acknowledgements}

The authors wish to thank Dr. Hideyuki Matsuura for providing the $(S)$-asfural; the Amino Up Chemical Co., Ltd. for providing the ETAS and the data concerning its ingredients; and Ms. Noriko Kanazawa for her secretarial assistance. This work was supported in part by research grants from the Ritsumeikan Global Innovation Research Organization (R-GIRO) of Ritsumeikan University and the Amino Up Chemical Co., Ltd.

\section{REFERENCES:}

1. López, G., G. Ros, F. Rincón, J. Ortuño, M.J. Periago, and M.C. Martínez. 1996. Amino acids and in vitro protein digestibility changes in green asparagus (Asparagus officinalis L.) during growth and processing. Food Res Int. 29: 617-625.

2. Negi, J.S., P. Singh, G.P. Joshi, M.S. Rawat, and V.K. Bisht. 2010. Chemical constituents of Asparagus. Pharmacogn Rev. 4: 215-220.

3. Ohno, N., E. Yoshigai, T. Okuyama, Y. Yamamoto, T. Okumura, K. Sato, Y. Ikeya, and M. Nishizawa. 2012. Chlorogenic acid from the Japanese herbal medicine Kinginka (Flos Lonicerae japonicae) suppresses the expression of inducible nitric oxide synthase in rat hepatocytes. HOAJ Biology. 1: 2.

4. Finka, A., S.K. Sharma, and P. Goloubinoff. 2015. Multi-layered molecular mechanisms of polypeptide holding, unfolding and disaggregation by HSP70/HSP110 chaperones. Front Mol Biosci. 2: 29.

5. Anckar, J., and L. Sistonen. 2011. Regulation of HSF1 function in the heat stress response: implications in aging and disease. Annu Rev Biochem. 80: 1089-1115.

6. Ito, T., A. Sato, T. Ono, K. Goto, T. Maeda, J. Takanari, H. Nishioka, K. Komatsu, and H. Matsuura. 2013. Isolation, structural elucidation, and biological evaluation of a 5-hydroxymethyl-2-furfural derivative, asfural, from enzyme-treated asparagus extract. J Agric Food Chem. 61: 9155-9159.

7. Sakurai, T., T. Ito, K. Wakame, K. Kitadate, T. Arai, J. Ogasawara, T. Kizaki, S. Sato, Y. Ishibashi, T. Fujiwara, et al. 2014. Enzyme-treated Asparagus officinalis extract shows neuroprotective effects and attenuates cognitive impairment in senescence-accelerated mice. Nat Prod Commun. 9: 101-106. 
8. Ito, T., T. Ono, A. Sato, K. Goto, T. Miura, K. Wakame, H. Nishioka, and T. Maeda. 2014. Toxicological assessment of enzyme-treated asparagus extract in rat acute and subchronic oral toxicity studies and genotoxicity tests. Regul Toxicol Pharmacol. 68: 240-249.

9. Lawrence, T. 2009. The nuclear factor NF-кB pathway in inflammation. Cold Spring Harb Perspect Biol. 1: a001651.

10. Kanemaki, T., H. Kitade, Y. Hiramatsu, Y. Kamiyama, and T. Okumura. 1993. Stimulation of glycogen degradation by prostaglandin $E_{2}$ in primary cultured rat hepatocytes. Prostaglandins. 45: 459-474.

11. Yoon, Y.J., J.A. Kim, K.D. Shin, D.S. Shin, Y.M. Han, Y.J. Lee, J.S. Lee, B.M. Kwon, and D.C. Han. 2011. KRIBB11 inhibits HSP70 synthesis through inhibition of heat shock factor 1 function by impairing the recruitment of positive transcription elongation factor $\mathrm{b}$ to the hsp70 promoter. J Biol Chem. 286: 1737-1747.

12. Green, L.C., D.A. Wagner, J. Glogowski, P.L. Skipper, J.S. Wishnok, and S.R. Tannenbaum. 1982. Analysis of nitrate, nitrite, and $\left[{ }^{15} \mathrm{~N}\right]$ nitrate in biological fluids. Anal Biochem. 126: 131-138.

13. Tanemoto, R., T. Okuyama, H. Matsuo, T. Okumura, Y. Ikeya, and M. Nishizawa. 2015. The constituents of licorice (Glycyrrhiza uralensis) differentially suppress nitric oxide production in interleukin-1 $\beta$-treated hepatocytes. Biochem Biophys Rep. 2: 153-159.

14. Inaba, H., E. Yoshigai, T. Okuyama, M. Murakoshi, K. Sugiyama, H. Nishino, and M. Nishizawa. 2015. Antipyretic analgesic drugs have different mechanisms for regulation of the expression of inducible nitric oxide synthase in hepatocytes and macrophages. Nitric Oxide. 44: 61-70.

15. Takimoto, Y., H.Y. Qian, E. Yoshigai, T. Okumura, Y. Ikeya, and M. Nishizawa. 2013. Gomisin $\mathrm{N}$ in herbal drug gomishi (Schisandra chinensis) suppresses inducible nitric oxide synthase gene via $\mathrm{C} / \mathrm{EBP} \beta$ and $\mathrm{NF}-\kappa \mathrm{B}$ in rat hepatocytes. Nitric Oxide. 28: 47-56.

16. Nakajima, A., Y. Yamamoto, N. Yoshinaka, M. Namba, H. Matsuo, T. Okuyama, E. Yoshigai, T. Okumura, M. Nishizawa, and Y. Ikeya. 2015. A new flavanone and other flavonoids from green perilla leaf extract inhibit nitric oxide production in interleukin 1 $\beta$-treated hepatocytes. Biosci Biotechnol Biochem. 79: 138-146.

17. Yoshigai, E., T. Hara, H. Inaba, I. Hashimoto, Y. Tanaka, M. Kaibori, T. Kimura, T. Okumura, A.H. Kwon, and M. Nishizawa. 2014. Interleukin-1 $\beta$ induces tumor necrosis factor- $\alpha$ secretion from rat hepatocytes. Hepatol Res. 44: 571-583. 
18. Matsui, K., M. Nishizawa, T. Ozaki, T. Kimura, I. Hashimoto, M. Yamada, M. Kaibori, Y. Kamiyama, S. Ito, and T. Okumura. 2008. Natural antisense transcript stabilizes inducible nitric oxide synthase messenger RNA in rat hepatocytes. Hepatology. 47: 686-697.

19. Yoshigai, E., T. Hara, T. Okuyama, T. Okumura, M. Kaibori, A.H. Kwon, and M. Nishizawa. 2012. Characterization of natural antisense transcripts expressed from interleukin 1 $\beta$-inducible genes in rat hepatocytes. HOAJ Biology. 1: 10.

20. Bachelerie, F., A. Ben-Baruch, A.M. Burkhardt, C. Combadiere, J.M. Farber, G.J. Graham, R. Horuk, A.H. Sparre-Ulrich, M. Locati, A.D. Luster, et al. 2014. International union of basic and clinical pharmacology. LXXXIX. Update on the extended family of chemokine receptors and introducing a new nomenclature for atypical chemokine receptors. Pharmacol Rev. 66: 1-79.

21. Nishizawa, M., Y. Ikeya, T. Okumura, and T. Kimura. 2015. Post-transcriptional inducible gene regulation by natural antisense RNA. Front Biosci (Landmark Ed). 20: $1-36$.

22. Zhong, C., C. Jiang, X. Xia, T. Mu, L. Wei, Y. Lou, X. Zhang, Y. Zhao, and X. Bi. 2015. Antihepatic fibrosis effect of active components isolated from green asparagus (Asparagus officinalis L.) involves the inactivation of hepatic stellate cells. J Agric Food Chem. 63: 6027-6034.

23. Ito, T., T. Maeda, K. Goto, T. Miura, K. Wakame, H. Nishioka, and A. Sato. 2014. Enzyme-treated asparagus extract promotes expression of heat shock protein and exerts antistress effects. J Food Sci. 79: H413-H419.

24. Ito, T., K. Goto, J. Takanari, T. Miura, K. Wakame, H. Nishioka, A. Tanaka, and J. Nishihira. 2014. Effects of enzyme-treated asparagus extract on heat shock protein 70, stress indices, and sleep in healthy adult men. J Nutr Sci Vitaminol (Tokyo). 60: 283290.

25. Okutsu, K., Y. Yoshizaki, N. Ikeda, T. Kusano, F. Hashimoto, and K. Takamine. 2015. Antioxidants in heat-processed koji and the production mechanisms. Food Chem. 187: 364-369.

26. Goldring, C.E.P., S. Reveneau, A. Chantome, A. Pance, C. Fleury, D.A. Hume, D. Sester, B. Mignotte, and J.F. Jeannin. 2000. Heat shock enhances transcriptional activation of the murine-inducible nitric oxide synthase gene. FASEB J. 14: 23932395. 
27. Xie, Y., C. Chen, M.A. Stevenson, P.E. Auron, and S.K. Calderwood. 2002. Heat shock factor 1 represses transcription of the IL-1 $\beta$ gene through physical interaction with the nuclear factor of interleukin 6. J Biol Chem. 277: 11802-11810.

28. Sakitani, K., M. Nishizawa, K. Inoue, Y. Masu, T. Okumura, and S. Ito. 1998. Synergistic regulation of inducible nitric oxide synthase gene by CCAAT/enhancerbinding protein $\beta$ and nuclear factor $\kappa \mathrm{B}$ in hepatocytes. Gene Cells. 3: 321-330.

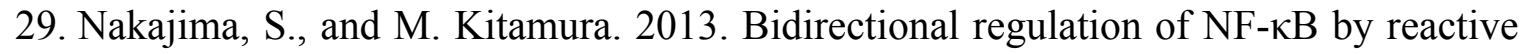
oxygen species: a role of unfolded protein response. Free Radic Biol Med. 65: 162174. 